\title{
Effects of the blood components on the AMPA and NMDA synaptic responses in brain slices in the onset of hemorrhagic stroke
}

\author{
Anatoly A. Mokrushin and Larisa I. Pavlinova \\ Laboratory of Regulation of Neuron Function, I. P. Pavlov Institute of Physiology of the Russian Academy of Sciences, \\ St-Petersburg, Russia
}

\begin{abstract}
Blood-borne events play a major role in post bleeding disturbances of the neuronal network. However, very little is known about the early effects of blood plasma, leucocytes, and the red blood cells on the AMPA and NMDA-mediated synaptic responses in the onset of experimental intracranial hemorrhage $(\mathrm{ICH})$. In this study, we used the technique of on-line monitoring of electrophysiological parameters referred to synaptic activity in piriform cortex of SHR rat slice. We exposed the olfactory cortex slices to diluted autologous blood or its components and compared with effects of ferric chloride. Whole blood exerted a total inhibition of synaptic activity in piriform cortex within first 5 min. Dilution of blood induced prolonged epileptic synaptic activation of NMDA receptors. Blood plasma and fraction of leucocytes induced hyperactivation of neurons transforming to epileptiform discharges. Fraction of red blood cells acted biphasic, an initial sharp activity of AMPA- and NMDAmediated receptors replaced by a following total depression. Our slice-based models of experimental stroke revealed the mechanism of the earliest pathophysiologic events occur in brain tissue during bleeding that may be relevant to the human ICH.
\end{abstract}

Key words: Brain slices - Autologous blood - Experimental stroke - Synaptic activity - AMPA and NMDA receptors — Bleeding — Epileptiform activity

\begin{abstract}
Abbreviations: AMPA, $\alpha$-amino-3-hydroxyl-5-methyl-4-isoxazole-propionate; AP LOT, presynaptic component FP; BCS, buffy coat suspension; EDs, epileptiform discharges; EPSP, excitatory post-synaptic potential; FPs, field potentials; ICH, intracerebral hemorrhage; IPSPs, slow inhibitory postsynaptic potentials; NMDA, N-methyl-d-aspartic acid.
\end{abstract}

\section{Introduction}

In spite of numerous clinical and experimental observations, the current understanding of a crucial pathophysiological mechanism of spontaneous intracerebral hemorrhage (ICH) is limited (Xi et al. 2006). The estimation of the neurophysiological network changes that occur in brain tissue during the early minutes of bleeding is unrealizable in available experimental models. Early modifications of synaptic responses induced by blood-borne events may predict the direction

Correspondence to: Larisa I. Pavlinova, Laboratory of Regulation of Neuron Function, I. P. Pavlov Institute of Physiology of the Russian Academy of Sciences, nab. Makarova 6, St-Petersburg, 199034, Russia

E-mail: lorhen45@gmail.com and timing of subsequent neuronal network during ICH and connect with the mechanism of local neuronal damage during cerebral bleeding (Lee et al. 2004; Fiehler 2006; Chen et al. 2008; Nishikawa et al. 2009). Cerebrovascular dysfunctions (Ueno 2009; Amenta et al. 2010) closely associated with chronic hypertension may provoke the expansion of damage and aggravate synaptic responses (Ariesen et al. 2003; Badjatia and Rosand, 2005; Zia et al. 2006; Poels et al. 2010). A widening of the early neuronal damage in the different brain regions during $\mathrm{ICH}$ is a result of increasing excitotoxicity mediated by glutamate activation of NMDA or AMPA receptors in brain tissue (Qureshi et al. 2003; Ardizzone et al. 2004; Liu et al. 2007; Lau and Tymianski 2010; Lai et al. 2011). Early acute hypersynchronous glutamatergic activation of cortical neurons leads to acute seizures and epilepsy (Herman 2002; DeLorenzo et al. 2007; Gilmore 
et al. 2010; Balami and Buchan 2012). Extravasated blood plasma components are toxic for brain neurons (Qureshi et al. 2003; Wagner 2007; Aronowski and Zhao 2011) and may induce the neuronal network failure.

The main goal of the present study is to verify how blood components per se are able to induce early changes in excitability of neurons leading to epileptogenesis. In this study, slice-based assay system has utilized to register the synaptic activity from the outset of bleeding. Acute brain slice models allow to recording the neuronal signals in living tissues in a normal or injured brain tissue (Cho et al. 2007). Slices largely preserve the tissue architecture of the brain regions that they originated from and maintain neuronal activities with intact functional local synaptic circuitry. We first developed a new ICH model on olfactory cortex slices; and with aid of this model we showed the ability of some endogenous substances to recover the synaptic activity in the damaged brain during bleeding (Khama-Murad et al. 2011; Mokrushin and Pavlinova 2012a, 2012b). The ascertained early synaptic events in the slice model may be relevant the neurons damage during the human ICH and microbleeding or rebleeding.

We propose that such in vitro model serves as an important tool for a novel interpretation of the mechanisms underlying the early and delayed brain damage after intracerebral bleeding.

\section{Materials and Methods}

\section{Experimental animals}

All animals used in this study were treated with observance of recommendations on ethics of work with the animals offered European Communities Council Direction (86/609 EEC). Animals were housed under standard 12:12-h light/ dark conditions and allowed free access to food and water. Olfactory cortex slices were prepared from brain of spontaneously hypertensive rat males (approximately $200 \mathrm{~g}$ body weight) taking into consideration that high blood pressure is known to represent a rather reliable prognostic factor of outcome of intracerebral hemorrhage (Ariesen et al. 2003; Zia et al. 2006). Systolic and mean blood pressure measurements (in triplicate) were taken using a noninvasive tail cuff blood pressure system. Systolic artery blood pressure and mean artery blood pressure of the rats were measured and values were $177 \pm 10 / 145 \pm 8 \mathrm{mmHg}$.

\section{Slice preparations}

The brain was rapidly removed, and dissected into left and right hemisphere (Fig. 1A, B). After decapitation, tangential slices about $400-500 \mu \mathrm{m}$ in thickness (Fig. 1C) prepared within 1 min using a glass guide and tissue chopper (Mokrushin 1997). Slices were maintained in artificial cerebrospinal fluid (aCSF), consisted of (in $\mathrm{mM}$ ): $\mathrm{NaCl}$ $124 ; \mathrm{KCl} 5 ; \mathrm{CaCl}_{2} 2.6 ; \mathrm{KH}_{2} \mathrm{PO}_{4} 1.24 ; \mathrm{MgSO}_{4} 1.2 ; \mathrm{NaHCO}_{3}$ 3; glucose 10; Tris-HCl 23 (Sigma, USA); equilibrated with $\mathrm{O}_{2}$, with osmolarity of 295-305 mOsm (OMT-5-01, "Burevestnic", Russia) for preincubation during $60 \mathrm{~min}$. Constant osmolarity was throughout experimental procedures within 295-305 mOsm (OMT-5-01, "Burevestnic", Russia). The concentrations of $\mathrm{Ca}^{2+}$ and $\mathrm{Mg}^{2+}$ were optimized for maximal synaptic activity in olfactory cortex. The temperature was $37^{\circ} \mathrm{C}, \mathrm{pH} 7.2-7.3$. Slices in $10 \mathrm{ml}$ of aCSF were incubated in glass vials in Warburg's apparatus (Germany) with oscillation frequency 120/min. These conditions allowed maintaining the vital activity of slices during 10-14 h and sometime more (Mokrushin 1997). After 60 min of incubation, the medium was exchanged for new portion with the obligatory oxygen bubbling of aCSF and air in glass vials. Such procedure eliminates the remains of destroyed cells, which can negatively influence the vital activity of slices. For extracellular recordings, slices sited on nylon netting were transferred to a recording chamber (Pavlov Institute Physiology, Russia) and were continuously perfused with aCSF with upper surface of each slice opened to the atmosphere humidified and heated to $37^{\circ} \mathrm{C}$. The automatically controlled rate of perfusion along with a continuous delivery of oxygen was equal to $2 \mathrm{ml} / \mathrm{min}$. A complete exchange of the solution in the recording chamber occurred in about $1 \mathrm{~min}$.

\section{Perfusion with the different amount of autologous blood and with the different fractions of autologous blood}

After preparation of slices, autologous blood from head arteries were collected in glass vials with concentration of heparin (Chimreactiv, Russia) equal to $0.4 \mathrm{mg} / \mathrm{ml}$ to prevent clotting. Heparinized autologous blood mixed with aCSF in the ratio $30,20,3$ or $0.5 \mathrm{ml}$ of blood with $50 \mathrm{ml}$ of medium. Synaptic responses in piriform cortex were registered during perfusion of slice with aCSF to determine the initial peak amplitudes of the separate field potentials (FPs) components (expressed as control). Then synaptic responses in the slice were recorded at time point $5,10,20,30$ and $40 \mathrm{~min}$ after continuous perfusion with aCSF containing a different amount of autologous blood. Oxygen delivery to a slice stopped at this time. For washout, a slice was perfused with oxygenated aCSF during $30 \mathrm{~min}$ and the FPs registered again. The amplitudes of the FPs components recorded at the defined time point of perfusion with autologous blood we compared with the initial peak amplitudes (control) and with those after washout. Thereby we determined both the levels of damaged and restored synaptic activity. 


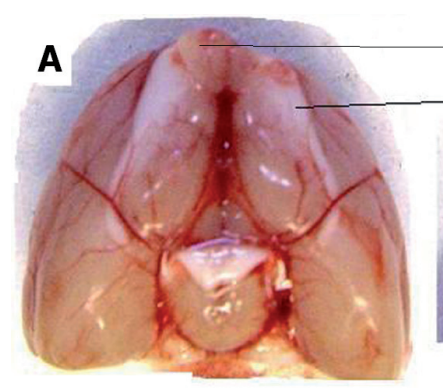

B

Olfactory C

C PC
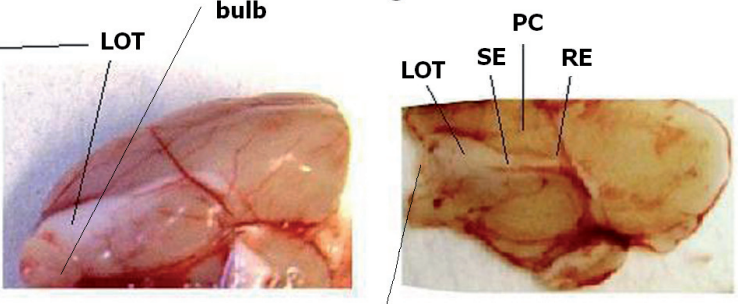

olfactory bulb cutoff

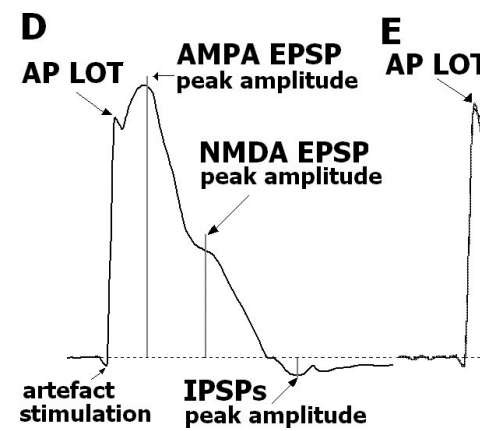

F

AP LOT AMPA EPSP

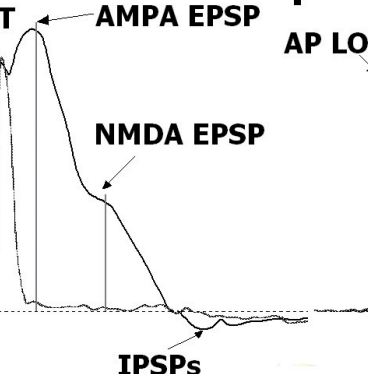

NMDA EPSP

IPSPs

Figure 1. Photographs of the whole brain from SHR rats from the pial side (A), half of the brain (B) for the subsequent slice preparation (C). LOT, lateral olfactory tract, formed by axons of mitral cells of the olfactory bulbs, in vivo LOT is the main afferent input to olfactory cortex structures; PC, piriform cortex, the basic structure of the olfactory sensory system; SE, stimulating electrode localization; RE, recording electrode localization. D. FPs in piriform cortex. Components of FPs recorded in piriform cortex of the olfactory cortex slice. Artefact stimulation - a mark of the stimulating impulse onset. AP LOT, total action potential of LOT fibers (presynaptic component of the field potentials). To eliminate antidromic stimulation of mitral neurons localized in olfactory bulbs, the latter were removed surgically in the process of the slice preparation. AMPA EPSP and NMDA EPSP, components of excitatory postsynaptic potential; IPSPs, slow $\left(\mathrm{GABA}_{\mathrm{B}} \mathrm{ergic}\right)$ inhibitory postsynaptic potential; dotted line, isoline; arrows show the measuring modes of amplitudes of individual FPs components. Pharmacological identification of postsynaptic excitatory components of FPs in the rat SHR olfactory cortex slices (E, F). Effects of CNQX and D-APV on modification of the FPs components in control medium. The FPs were recorded in response to LOT (proximal end) fiber stimulation in every experiment before (control) and during perfusion with $25 \mu \mathrm{M} \mathrm{CNQX}(n=18)$ and with DAPV $(50 \mu \mathrm{M})$ in a medium with low concentration of the $\mathrm{Mg}^{2+}(200 \mu \mathrm{M})(n=16)$. Dotted line, isoline; vertical lines, the points of the measuring of the amplitudes of the FPs components, correlatively to artefact stimulation. Calibration: $0.1 \mathrm{mV}$ and $5 \mathrm{~ms}$.

Before to start the experiments with the components of autologous blood we have analyzed the effects of heparin on the FPs in piriform cortex. Heparin in concentration up to $2 \mathrm{mg} / \mathrm{ml}$ does not change the peak amplitudes of excitatory a-amino-3-hydroxy-5-methylisoxalol-4-propionic acid (AMPA) and N-methyl-D-aspartate (NMDA) excitatory postsynaptic potentials (EPSP) as well as inhibitory GABA inhibitory postsynaptic potential (IPSPs) (Mokrushin and Pavlinova 2012).

The fractions of blood were separated by centrifugation of heparinized autologous blood at $1500 \times g$ during $20 \mathrm{~min}$ (Elekon CLMN P10-01, Russia). We obtained three fractions: an autologous blood plasma, a buffy coat suspension (BCS) and an erythrocyte fraction. Microscopic findings showed that first fraction corresponded to autogenic plasma, second fraction consisted of platelets and leukocytes in plasma with the erythrocyte traces, the third fraction contained red blood cells. These fractions of autologous blood kept at $+4^{\circ} \mathrm{C}$ up before its using in the electrophysiological experiments. The fractions were tested about as follows: the erythrocyte fraction - usually within 5-7 min after the blood fractionating; fractions of an autologous blood plasma and BCS were tested within 40-50 min after the blood fractionating. Reorder of the fraction testing did not affect significantly on the effects caused by these factions.

Electrophysiological stimulation and recordings from olfactory cortex slices

During electrophysiological experiments, slices were observed with a binocular microscope MBS-2 (Russia) in a recording chamber. FPs were evoked using platinum bipolar stimulating electrodes with a tip separation of $0.5 \mathrm{~mm}$ positioned onto the proximal part of the lateral olfactory tract (LOT) - the main input of afferent impulses to neurons of olfactory cortex. In order to get a clear record 
of all main components of FP, microelectrode was initially focused on the pial surface, and then injected into slice at a certain depth (Mokrushin 1997). The microelectrode was advanced in slice by steps of 1 or $10 \mu \mathrm{m}$, as determined by an electronic indicator of a micromanipulator (NTO, Russia). The electrode track was about $40^{\circ}$ to the horizontal. However, the slice pial surface is not flat; no correction was attempted for any deviation of pial surface of slice from the horizontal. Zero depth was taken as the level where there was a sudden potential jump when the microelectrode was lowered into contact with the slice surface. Under these conditions, the most pronounced FPs were in a point indicated in 270-300 $\mu \mathrm{m}$ depth from pial surface of the slice, and the recording point was located in this focus of maximal activity (Musiashchikova and Mokrushin 1989).

Orthodromic stimulation of LOT imitated the flows of afferent impulses coming from the mitral neurons of the olfactory bulb in vivo. The rectangular pulses with duration of $0.05-0.1 \mathrm{~ms}$ and the intensity of $1-3 \mu \mathrm{A}$ were evoked with aid of the constant current stimulator (ESU-1, Russia) through platinum custom-made bipolar concentric electrode insulated at the cut ends. Frequency of LOT electric stimulation equal to $0.003 \mathrm{~Hz}$ was infrequent to eliminate the development of a habituation in olfactory neurons in answer to repeated stimulation.

FPs from slices were recorded using a glass microelectrode. Glass microelectrodes were pulled from 1.5-mm o.d. capillary tubing with a ME 1 vertical puller (Russia). A tip resistance of microelectrode filled with $1 \mathrm{M} \mathrm{NaCl}$ was $1-5$ $\mathrm{M} \Omega$. FPs recordings were performed using an NTO-2 amplifier (Russia). The silver reference electrode was located in a chamber floor.

Synaptic responses induced in piriform cortex reflect the entering and information processing. They are conditioned by the different mechanisms of electrogenesis in olfactory neurons. We analyzed the following individual components of FPs: the compound action potential of the lateral olfactory tract (AP LOT, presynaptic component FP), and the nonNMDA (nNMDA) and NMDA receptor components of EPSPs. The first of these postsynaptic components is activated by AMPA, the second with NMDA (Hoffman and Haberly 1989; Jung et al. 1990; Mokrushin 1997), referred to as AMPA and NMDA EPSPs. A slow (GABA ${ }_{B}$ ergic) IPSPs is generated at $\mathrm{GABA}_{\mathrm{B}}$ receptors activation (Satou et al. 1982; Tseng and Haberly 1988). To eliminate antidromic stimulation of mitral neurons localized in olfactory bulbs, the latter were removed surgically in the process of the slice preparation.

Under normal conditions in piriform cortex, stimulation of proximal part of LOT evoked FPs with the fast EPSP component mediated by AMPA receptors and the late component of EPSP mediated by activation of the NMDA receptors. Typical trace of the evoked FP in piriform cortex is presented in Fig. 1D. For electrophysiological recording, each slice was perfused with aCSF and the pre- and postsynaptic components of evoked FP were registered before testing of blood or blood components. The initial peak amplitudes of this evoked FP compared with the same at the time of blood/blood components action.

\section{Data analysis}

We used the technique of controlled experiment by computer to standardize conditions of individual experiments. The intensity of stimulation and the intervals and quantity of stimuli delivered to LOT were specified. After each stimulus the FPs were processed in the on-line mode. The FPs were amplified with the analog-digital converter MD-32 (Russia) (sample rate $25 \mathrm{kHz}$ ), and transmitted to computer for registration and subsequent analysis using special homemade software. Amplitudes of FPs components we estimated from the isoline to the peak level. The amplitudes of AMPA EPSP we assessed within a 1.5-2 ms window centered at the peak of the response. Peak NMDA EPSP was measured as the average potential observed in a 7-8 ms window (Mokrushin 1997) (Fig. 1D).

\section{Statistical analysis}

Statistical comparisons were performed with nonparametric Wilcoxon-Mann-Whitney U test. Numerical data were expressed as mean \pm standard error of the mean (S.E.M.). The level of statistical significance was set at $p<0.05$.

\section{Results}

\section{Pharmacological identification of postsynaptic excitatory components of the FPs in the rat olfactory cortex slices.}

During perfusion of slices with aCSF the stimulation of proximal part of LOT evoked FPs in piriform cortex (Fig. 1D). For identification of these receptors in piriform cortex under control electrophysiological recording, we used specific antagonists of the AMPA and NMDA ionotropic glutamate receptors: CNQX (6-cyano-7-nitroquinoxaline2, 3-dione; a competitive antagonist of AMPA/kainate glutamate receptors) and D-APV (D-2-amino-5-phosphonovalerate; a competitive antagonist of NMDA glutamate receptors). The FPs were recorded in response to stimulation of the LOT proximal part in every experiment before (control) and during perfusion with specific antagonists. For the AMPA EPSP identification, we added CNQX after the baseline recordings during $15 \mathrm{~min}$. Addition of CNQX to the perfusion medium completely abolished postsynaptic responses generated by LOT stimulation (Fig. 1E). This inhibition of the postsynaptic components was within $20-25 \mu \mathrm{M}$ concentration of CNQX $(n=18)$. These results indicate that 
under normal conditions LOT evoked fast component EPSP mediated by AMPA receptors in piriform cortex.

For the NMDA EPSP identification, we applied $50 \mu \mathrm{M}$ of D-APV. In order to prevent the blockage of these receptors by $\mathrm{Mg}^{2+}$, the slices $(n=16)$ were washed with a medium with low $\mathrm{Mg}^{2+}$ concentration $(200 \mu \mathrm{M})$ during $20 \mathrm{~min}$. Lowering $\mathrm{Mg}^{2+}$ caused a small increase in the peak amplitude of AMPA EPSPs, but the amplitude of presynaptic component was not changed. This slight increase in the amplitude of
AMPA EPSP may reflect the increase in transmitter release from presynaptic terminals as well as and increase depolarization of the postsynaptic membranes.

Application of $50 \mu \mathrm{M}$ D-APV reduced the late component of the EPSP mediated by activation of the NMDA receptors (Fig. 1F). It is obviously, that the late component EPSP mediated by activation of the NMDA receptors. Further, we considered these fast and late components of FPs as EPSPs mediated by activation of the AMPA and NMDA receptors, accordingly.
A
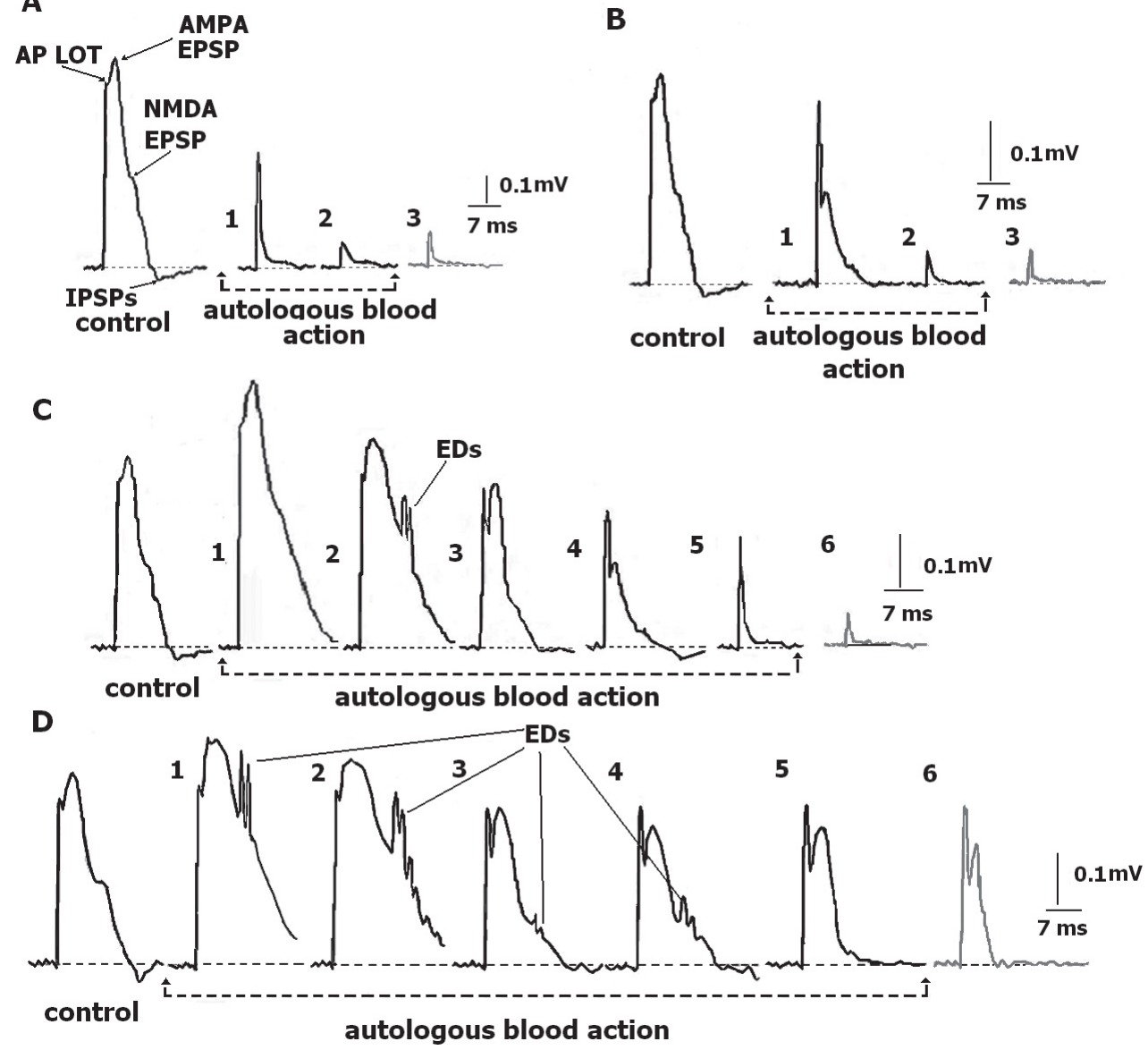

B

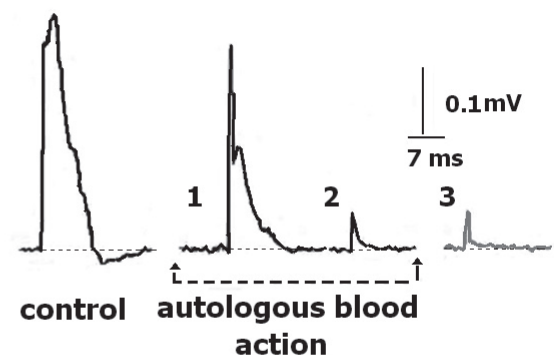

Figure 2. Representative traces of synaptic responses recorded in piriform cortex during perfusion with autologous blood. A. Synaptic events (FPs) recorded in neurons of piriform cortex during perfusion with $30 \mathrm{ml}$ of wholecompletely autologous blood in $50 \mathrm{ml}$ of aCSF. B. FPs recorded during perfusion with $20 \mathrm{ml}$ of autologous blood in $50 \mathrm{ml}$ of aCSF. C. FPs recorded in neurons of piriform cortex during perfusion with $3 \mathrm{ml}$ of autologous blood in $50 \mathrm{ml}$ of aCSF. D. FPs recorded in neurons of piriform cortex during perfusion with $0.5 \mathrm{ml}$ of autologous blood in $50 \mathrm{ml}$ of aCSF. Horizontal dotted line - isoline. EDs - epileptiform discharges. At the FPs registration, the electronic device for artefact-rejection was used. Note, that (A and B) wholecompletely autologous blood induced total suppression of postsynaptic responses, the washout failed to restore these responses. Dilution of autologous blood led to appearance of epileptic discharges on NMDA-mediated EPSP. Biphasic changes of the amplitudes of excitatory glutamatergic AMPA and NMDA mediated mechanisms were observed: the initial short-term increasing then followed by a phase of depression and eventually by the subsequent blockade of synaptic glutamate responses (C). The inhibitory $\mathrm{GABA}_{\mathrm{B}} \mathrm{ergic}$ mechanism (IPSPs) was more vulnerable to autologous blood action. The postsynaptic mechanisms were blocked irreversibly. Further dilution of autologous blood resulted in epileptic discharges of NMDA-mediated mechanisms (EDs) during 30 min, which then terminated without restoration after washout. Amplitudes of AMPA EPSP slightly decreased but were significant. The amplitudes of presynaptic component - AP LOT were steadfast during whole time of perfusion and washout. Inhibitory GABA $\mathrm{B}_{\mathrm{B}}$ ergic (IPSPs) and NMDA-mediated mechanisms were blocked irreversibly after 40 min of perfusion (D). Horizontal dotted line, isoline; EDs, epileptiform discharges. 
Synaptic responses in piriform cortex induced by perfusion of slices with whole and diluted autologous blood

In order to ascertain how the onset of the blood contact with brain neurons resulted in their synaptic efficacy, we examined synaptic responses in piriform cortex during perfusion with different amount of wholecompletely autologous blood diluted in aCSF (Fig. 2).

Perfusion of slices with $30 \mathrm{ml}$ of whole blood in $50 \mathrm{ml}$ of aCSF min induced the total depression of postsynaptic responses at first $5 \mathrm{~min}$. The only reduced activity of conductive fibers of LOT was maintained at this time $(65.0 \pm 15.0 \%$, $U=17, n=7, p<0.05)$. Further perfusion led to profound decrease of AP LOT at $10 \mathrm{~min}$. A typical recording of the FPs was the same as presented in (Fig. 2A). The washout failed to restore the postsynaptic activity although reduced presynaptic response persisted.

Perfusion of brain slices during $5 \mathrm{~min}$ with $20 \mathrm{ml}$ of whole blood in $50 \mathrm{ml}$ of aCSF resulted in a decreased synaptic efficacy of the olfactory neurons (Fig. 2B). Postsynaptic glutamate response was reduced $(57.0 \pm 9.5 \%$ for AMPA EPSP and $23.5 \pm 7.0 \%$ for NMDA EPSP of peak amplitudes in control, $U=14$ and $U=10$, respectively, $n=8, p<0.05$ ). $\mathrm{GABA}_{\mathrm{B}}$ ergic postsynaptic transmission was blocked at this time. At $20 \mathrm{~min}$ of perfusion the postsynaptic components were quite blocked and only reduced AP LOT was recorded $(17.7 \pm 3.5$ as compared to peak amplitudes in control, $U=11, n=8, p<0.05)$. The washout failed to restore postsynaptic responses and to increase AP LOT although the blood has been diluted.

From clinics, it is known that microbleeds often occurred without any neurological features. To study how a small blood amount has an influence on activity of neurons, we examined the progression of synaptic efficacy during perfusion with diluted autologous blood ( 3.0 and $0.5 \mathrm{ml}$ in $50 \mathrm{ml}$ of aCSF) (Fig. 2C and D).

The onset of perfusion with the diluted blood $(3.0 \mathrm{ml}$ in $50 \mathrm{ml}$ of aCSF) resulted in synaptic firing of excitatory glutamate potentials during $10 \mathrm{~min}$ (Fig. 2C). Diluted blood provoked a sharp activation of excitatory postsynaptic processes after the first $5 \mathrm{~min}$ of perfusion. The amplitudes of AMPA EPSP reached $140.0 \pm 12.0 \%, U=89, n=21$ and of NMDA EPSP - $178.0 \pm 15.0 \%, U=74, n=21$. On the contrary, $\mathrm{GABA}_{\mathrm{B}}$ ergic transmission was depressed at this time, amplitude of IPSPs consisted $5.0 \pm 3.0 \%(U=14, n=21, p<$ 0.01 ) of a control value.

After 10 min of perfusion, the spontaneous epileptiform discharges (EDs) appeared on the descending phase of NMDA EPSP. As perfusion continued, a progressive fading of the amplitudes of AP LOT, AMPA and NMDA EPSP (at $20-30^{\text {th }} \mathrm{min}$ ) was observed. The total blockade of postsynaptic components developed to $40^{\text {th }}$ min (Fig. 2C5). Such reduction of glutamatergic postsynaptic responses was persistent because washout failed to recover the amplitudes of FPs (Fig. 2C6). Presynaptic responses maintained during time of perfusion, declined progressively. Therefore, the excitotoxicity of the ionotropic glutamate receptors is believed to be in first five minutes of the onset of bleeding.

To specify the role of these receptors in the development of excitotoxicity, further experiments with the appreciably diluted blood ( $0.5 \mathrm{ml}$ in $50 \mathrm{ml}$ of aCSF) were performed (Fig. 2D). Interestingly enough, the hyperexcitability of glutamate postsynaptic components took place at first $10 \mathrm{~min}$ also. The total depression of the inhibitory $\mathrm{GABA}_{\mathrm{B}}$ ergic receptors occurred at the same time. Later on, the amplitudes of AMPA and NMDA EPSP decreased, but permanent EDs abounded on NMDA EPSP (Fig. 2D1-4). Shifting of the excitation/inhibition balance to abnormal excitatory synaptic transmission was accompanied by the EDs induction. It possibly may explain the appearance of the ictal epileptiform seizures observed in the patients with bleeding.

We hypothesized that the earliest multidirectional changes in synaptic efficacy and their time course may be conditional by an influence of the different constituents of a blood. Therefore, the intent of next series of experiments was to investigate how a defined blood component directly influences on the synaptic mechanisms in piriform cortex.

\section{Dual synaptic responses induced by perfusion of slices with autologous blood plasma}

As is known, after a cerebral hemorrhage, oxidations in the hematoma produce a cocktail of dangerous metabolites released into the brain's parenchyma (Wagner et al. 2003; Clark et al. 2008). To investigate if excitation of glutamatergic EPSPs and inhibition of GABA $\mathrm{B}_{\mathrm{B}}$ ergic IPSPs observed in piriform cortex in the onset of perfusion with autologous blood was dependent on the influence of different products of blood (clot) degradation, we performed experiments to examine the changes of synaptic activity in slices under the influence of the fractions derived from the blood centrifugation. Further, we experimented with the diluted autologous blood plasma ( $0.5 \mathrm{ml}$ per $50 \mathrm{ml}$ in aCSF) (Fig. 3 ).

The onset of perfusion with blood plasma induced synaptic firing of excitatory glutamate potentials. Epileptiform activity persisted for the duration of the recording (40 min) (Fig. 3A). We observed the spontaneous high-frequency EDs on AMPA and NMDA EPSP and total inhibition of IPSPs in the majority of slices (63\%) during perfusion of the autologous blood plasma. Washout of slices enabled to cease EDs, nevertheless NMDA EPSP amplitude was increased $(142.0 \pm 11.0 \%, U=7$, $n=12, p<0.05)$. IPSPs amplitude recovered after washout too $(123.5 \pm 12.0 \%, U=9, n=12, p<0.05)$ (Fig. 3B2).

In one third of slices (37\%) all FPs components appeared to be extremely depressed during time of perfusion with plasma (Fig. 3C and D). Postsynaptic responses of neurons in these 
slices were quite absent; the amplitude of AP LOT was missing, too. Washout restored the amplitudes of FPs to the control values. However, NMDA EPSP recovered incompletely (67.2 $\pm 12.5 \%, U=10, n=12, p<0.05$ ) (Fig. 3D2). It is essential to note that washout resulted in repairing of synaptic activity mediated by $\mathrm{GABA}_{\mathrm{B}}$ ergic receptors. Such synaptic responses of piriform cortex during perfusion with autologous blood plasma possibly reflected the reversible damage of neurons owing to the influence of plasma components.

Perfusion of slices with a buffy coat suspension from autologous blood augments glutamate postsynaptic responses in piriform cortex

Neurons of piriform cortex manifested spontaneous EDs on NMDA EPSP both the onset and before the termination of perfusion with a buffy coat suspension (BCS) ( $1 \mathrm{ml}$ in $50 \mathrm{ml}$ of aCSF).

Epileptiform activity persisted for the duration of the first eight minutes, then ceased for seven minutes and recommenced again. The maximal NMDA EPSP amplitude was $175.5 \pm 12.0 \%, U=11, n=12, p<0.05$ (Fig. $4 \mathrm{~A} 1$ and 3 ). In these series of experiments, a reversible reduction of the inhibitory processes was observed too. The washout differently affected the activity of the receptors. Synaptic responses of the conductive fibers of LOT and AMPA-mediated processes restored almost to control peak amplitudes. The activity of NMDA-mediated mechanism has arisen but the value of the NMDA EPSP component not exceeded $28.5 \pm 11.0 \%, U=12$, $n=12, p<0.05$, from the control level (Fig. 4B4). It is possibly may be explained by the difficulty of its renewal after the hyperexcitability of receptors and the intensity of EDs.
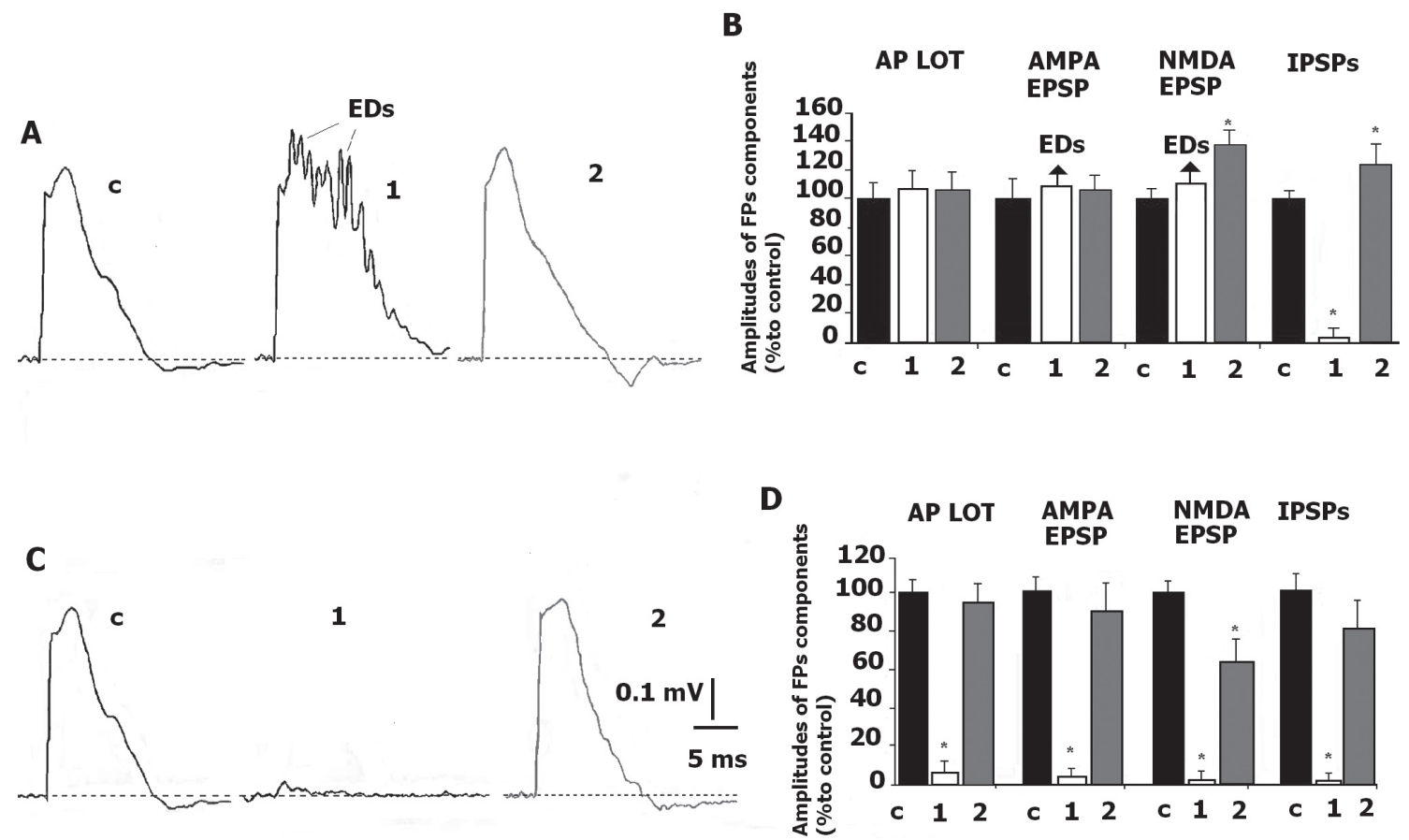

Figure 3. Perfusion with the autologous blood plasma induced a dual synaptic response in piriform cortex. The blood plasma obtained by the centrifugation of autologous blood with heparin (see Materials and Methods) was diluted in aCSF $(0.5 \mathrm{ml}$ per $50 \mathrm{ml}$ in aCSF). A. Representative traces showing synaptic events (FPs) recorded in the neurons of piriform cortex (63\% of the tested slices) in control conditions (c), FPs with epileptiform discharges (1) at the time of perfusion (0-40 min) and after washout from blood during $30 \mathrm{~min}$ with aCSF (2). B. Histograms representing the amplitudes of the FPs components in control conditions (c), during autologous blood plasma perfusion (1) and after washout with aCSF during $30 \mathrm{~min}$ (2) expressed as percentage of control, $n=9$ for every point; ${ }^{\star} p<0.05$. C. Representative traces showing synaptic events (FPs) recorded in the neurons of piriform cortex (37\% of the tested slices) in control conditions (c), FPs at the time of perfusion (0-40 min) (1) and after washout from blood during 30 min with aCSF (2). D. Histograms representing the amplitudes of the FPs components in control conditions (c) and during autologous blood plasma perfusion (1), after washout with aCSF during $30 \mathrm{~min}(2)$ expressed as percentage of control, $n=2$ for every point; ${ }^{\star} p<0.05$. Note, that autologous blood plasma affected the excitatory glutamatergic processes in two ways. Epileptiform activity persisted for the duration of perfusion in two thirds of neuron. At the same time in one third of neurons, the electrogenesis was completely depressed. Washout recovered synaptic responses in all neurons of piriform cortex. Horizontal dotted line, isoline; EDs, epileptiform discharges. Calibration: $0.1 \mathrm{mV}, 5 \mathrm{~ms}$. At the FPs registration the electronic device for artefact-rejection was used. 
It is noteworthy, that the $\mathrm{GABA}_{\mathrm{B}}$ ergic responses which are totally inhibited during perfusion with BCS, after washout increased to $147.5 \pm 13.0 \%$ of the control, $U=30, n=12$, $p<0.05$ (Fig. 4B4).

These data denote the ability of neurons to the excitatory/inhibitory balance revival. As microscopic evaluation have shown the BCS blood fraction consisted generally of the leucocytes with traces of the platelets and erythrocytes. The results of the experiments with the BCS fraction may explain the processes that occur in the brain of patients with the damaged blood-brain barrier permeability when the different blood components extravasated from the brain vessels into the surrounding area and induce the hyperexcitability of adjacent neurons with the appearance of the limited EDs.

\section{Synaptic depression in piriform cortex caused by perfusion} of slices with the erythrocyte fraction of autologous blood

To test the synaptic events in piriform cortex during contact of slice with erythrocyte fraction we used the suspension of red blood cells in aCSF ( $1 \mathrm{ml}$ in $50 \mathrm{ml}$ of aCSF) (Fig. 5).
This fraction of autologous blood induced a sharp epileptiform activity on glutamatergic components of FPs in the outset of perfusion (1-3 min). Then, we observed the whole depression of synaptic response over a period of perfusion. As in the previous variants of experiment with autologous blood, the GABA $\mathrm{B}_{\mathrm{B}}$ ergic synaptic activity completely depressed in the onset of contact with blood (Fig. 5A and D). The effects of erythrocyte fraction on synaptic efficacy in piriform cortex were reversible after washout.

Thus, each fraction of blood tested apart from the others induced an intrinsic effect which was mainly exciting for postsynaptic glutamatergic components but with different time courses. The total depression of the $\mathrm{GABA}_{\mathrm{B}}$ ergic synaptic responses in piriform cortex was illustrative in the time of the EDs appearance.

Synaptic responses in piriform cortex induced by perfusion of slices with ferric ions in aCSF

In consideration of the damaging effect of iron on the brain tissue during bleeding (Wagner et al. 2003; Zecca et al. 2004),
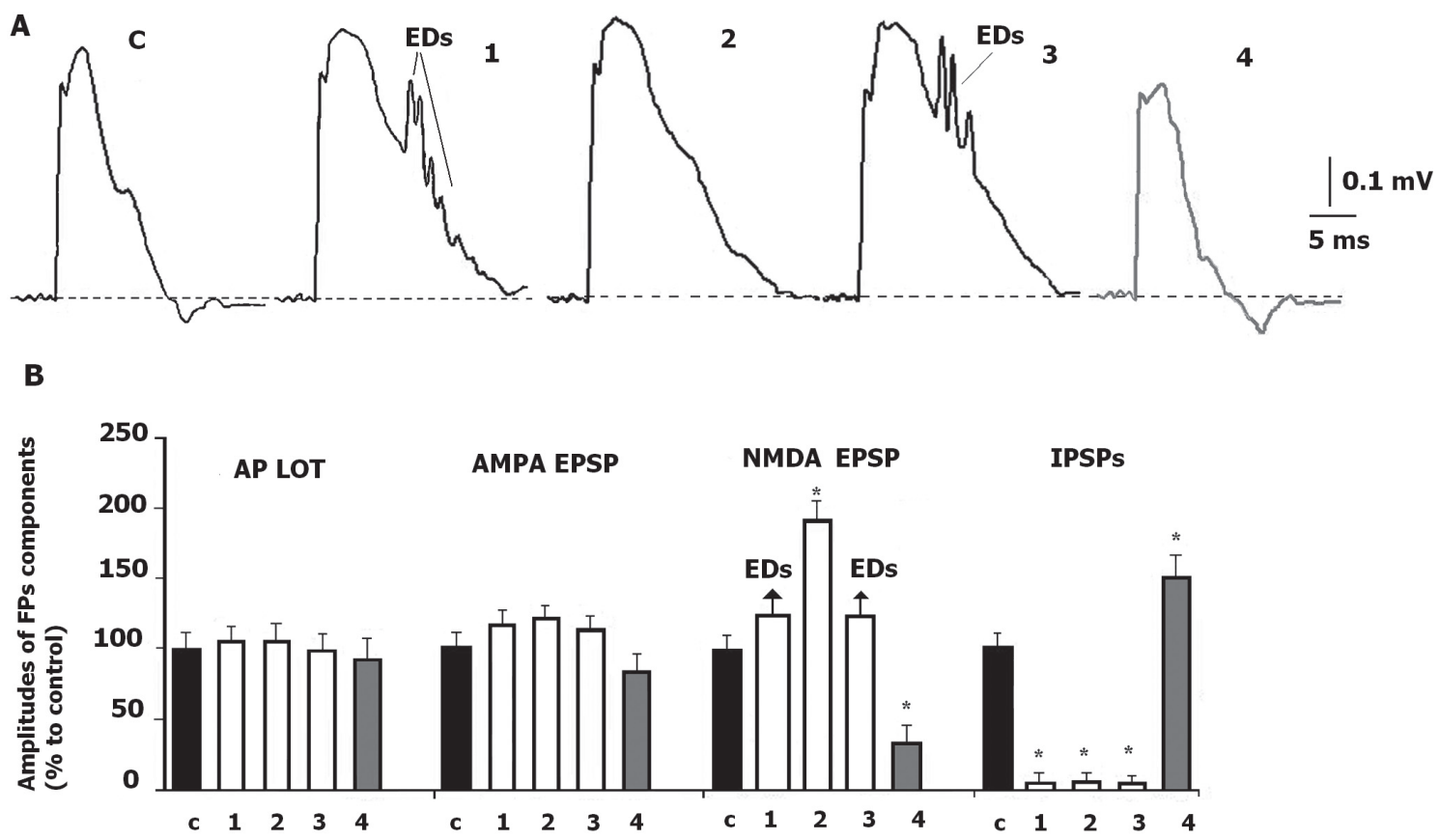

Figure 4. Electrogenesis in piriform cortex during perfusion with a buffy coat suspension (BCS). In our experiments, BCS consisted of the suspension of platelets and leukocytes with trace of erythrocytes in autologous blood plasma. The dynamics of AMPA and NMDA EPSPs tested in neurons of brain slices during perfusion with $1 \mathrm{ml}$ of BCS in $50 \mathrm{ml}$ of aCSF. A. Representative traces showing synaptic events (FPs) recorded in the neurons of piriform cortex in control conditions and perfusion with the fraction (1-8 min) (1). The EDs were observed in a descending phase of NMDA EPSP. 2, FPs during the 8-15 min of perfusion; 3, FPs during 15-40 of perfusion with EDs; 4, washout during 30 min with aCSF. B. Histograms representing the amplitudes of the FPs components expressed as percentage of control, $n=12$ for every point, ${ }^{\star} p<0.05$. Note, that BCS of the autologous blood increased excitability of NMDA mediated mechanism. This process was partially reversible. Washout restored depressed IPSPs. Horizontal dotted line, isoline; ED, epileptiform discharges. Calibration: $0.1 \mathrm{mV}, 5 \mathrm{~ms}$. At the FPs registration the electronic device for artefact-rejection was used. 
we examined the synaptic events in piriform cortex during perfusion of slices with the different ferric ion concentrations (Fig. 5B and C). Minimal free iron level in normal rat brain is a micromolar concentration, and it increased after intracerebral hemorrhage (Wagner et al. 2003). Firstly, we examined the effect of $25 \mu \mathrm{M} \mathrm{FeCl}_{3}$ applications to ascertain the role of iron on synaptic activity in olfactory cortex. Ferric ions induced decrease of amplitude of AMPA EPSP (38.5 $\pm 12.0 \%$, $U=15, n=12, p<0.05)$. EDs appeared on the NMDA EPSP. Washout failed to restore normal synaptic responses, because EDs arose on increased AMPA component (Fig. 5B).

To elucidate a synaptic transmission under ascending level of iron, we repeated our experiments with $100 \mu \mathrm{M}$ of $\mathrm{FeCl}_{3}$. Higher ferric ion concentration during $40 \mathrm{~min}$ perfusion evoked an increase in NMDA EPSP with nascent EDs, which were on AMPA EPSP too (Fig. 5C). Therefore, iron produced the excitatory and concentration dependent effect on glutamatergic processes in piriform cortex. This effect was slightly reversible, washout failed to eliminate EDs. It is important that iron had no significant influence on inhibitory $\mathrm{GABA}_{\mathrm{B}}$ ergic mechanisms.

\section{Discussion}

In present study, we applied slice-model system to elucidate the early modification of synaptic transmission in neurons of the SHRs olfactory cortex slices with neurovascular dysfunction (Amenta et al. 2010) from the outset of the acute contact with autologous blood and its components. The increasing in extracellular glutamate level, glucose metabolism in perihematomal area and neuronal cell death observed at early time of ICH (Qureshi et al. 2003; Ardizzone et al. 2004; Wagner 2007; Qureshi et al. 2009). The spreading excitotoxicity in

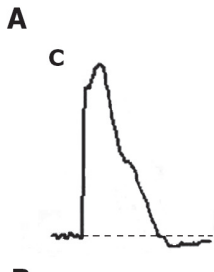

B

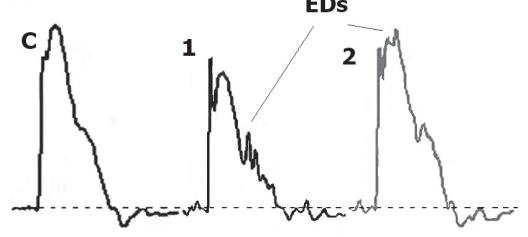

C

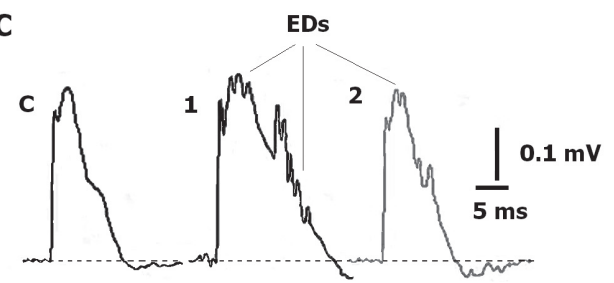

2

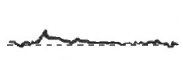

D
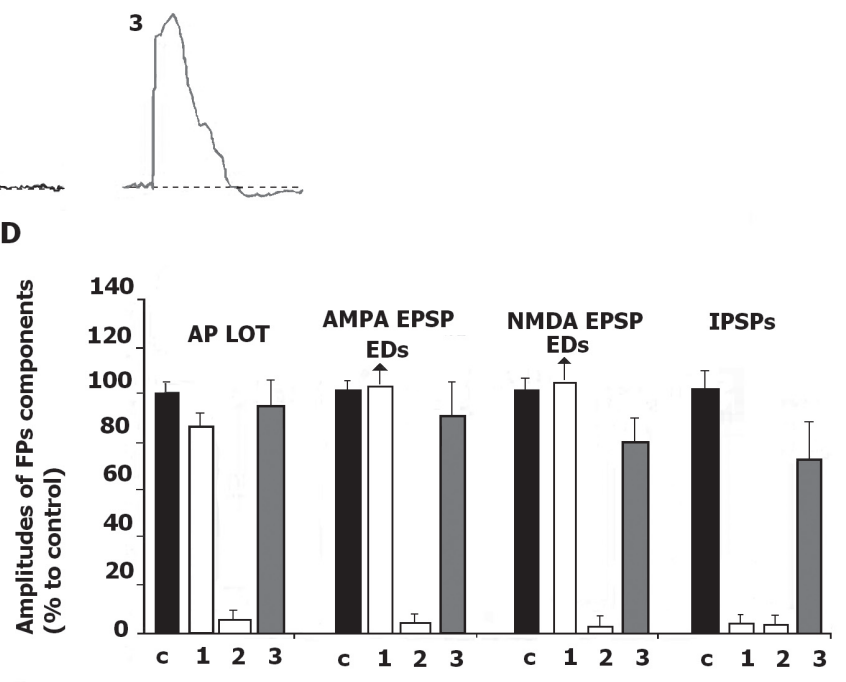

Figure 5. Electrogenesis in piriform cortex during perfusion with the erythrocyte fraction ( $1 \mathrm{ml}$ in $50 \mathrm{ml}$ of aCSF). This fraction consisted of the suspension of erythrocytes with traces of autologous blood plasma. A. Representative traces showing synaptic events (FPs) recorded in the neurons of piriform cortex in control conditions (c) and after perfusion (1) with the erythrocyte fraction (1-3 min). Appearance of the epileptiform discharges in AMPA and NMDA components of FPs. 2, FPs during the 3-40 min of perfusion; 3, washout during 30 min with aCSF B, C. Representative traces showing synaptic events (FPs) recorded in the neurons of piriform cortex perfusion with an aqueous solution of ferric chloride. Two concentration of ferric ions in aCSF $-25 \mu \mathrm{M}(\mathrm{n}=15)$ and $100 \mu \mathrm{M}(\mathrm{n}=12)$ were tested. $\mathrm{c}$, control, 1, perfusion with $\mathrm{FeCl}_{3}$ during $40 \mathrm{~min}, 2$, washout with aCSF (30 min). Note, that ferric ions induced the EDs appearance in the descending phase of NMDA EPSP. Higher $\mathrm{FeCl}_{3}$ concentration had a great effect on electrogenesis in slices. Ferric ions increased the amplitudes of postsynaptic components of FPs, with EDs on AMPA and NMDA components. Such excitability was not reversible with washout. Horizontal dotted line, isoline; EDs, epileptiform discharges. Calibration: $0.1 \mathrm{mV}, 5 \mathrm{~ms}$. At the FPs registration the electronic device for artefact-rejection was used. D. Histograms representing the amplitudes of the FPs components during perfusion with erythrocyte fraction expressed as percentage of control, $n=12$ for every point; ${ }^{\star} p<0.05$ Note, that the erythrocyte fraction of autologous blood increased an excitability of glutamate mediated mechanism in the first moment of application. Then, electrogenesis in slices depressed. This process was reversible. 
brain tissue mediated by glutamate activation of NMDA or AMPA receptors results in a widening of the secondary neuronal damage in the different brain regions (Lee et al. 1999; Liu et al. 2007; Lau and Tymianski 2010; Lai et al. 2011; Lok et al. 2011). The findings of the study showed how fast the waves of excitotoxicity spread in the brain tissue after contact with blood. It is obviously that such time-correlated hyperactivation of glutamate receptors may contribute to the expansion of cell injury in adjacent brain regions and during all time of the hematoma degradation

\section{Effects of whole and diluted autologous blood on synaptic activity}

Our results demonstrate that autologous blood induced instantaneous depression of synaptic activity of neurons within first five minutes. It is quite possible a sign of their irreversible destruction. The time course of such depression depended on the amount of blood contacted with neurons in piriform cortex of the brain slices. This rapid synaptic effect mimics a bleeding in cortex, where contact of neurons with autologous blood leads to depression of neuronal excitability.

To identify the time course of the earliest changes in synaptic responses in the neurons in perihematomal area, we have used a technique of blood dilution and have exposed the slices to the blood diluted with aCSF in the varied proportions. We first established that a level of blood dilution correlated with clearly defined increasing effect of the glutamate receptor excitation in piriform cortex. It is important that diluted blood induced more prolonged epileptiform synaptic activation of NMDA receptors (Fig. 2).

Such events may correlate with the neuronal synaptic distress happened in brain in the moment of the vascular rupture and bleeding. These results showed that the rate of the synaptic component degradation depends on the complexity of their location and organization. The early disruption of $\mathrm{GABA}_{\mathrm{B}}$-mediated activity may be a result of direct access of these receptors to a blood penetrating into brain parenchyma. Indeed, there are evidences that synapses mediated $\mathrm{GABA}_{\mathrm{B}}$ ergic inhibitory processes in olfactory cortex concentrated on pyramidal cell dendrites (Satou et al. 1982; Tseng and Haberly 1988). On the contrary, the excitatory postsynaptic receptors are localized on the soma of pyramidal neurons. Therefore, NMDA and especially AMPA-mediated mechanisms are more resistant to the blood influence and there is a time-lag of the damaging blood effect. The mechanisms of excitation along the LOT fibers were more stable possibly due to their closely fit and the dense myelin sheaths except for Ranvier's isthmus (Musiashchikova and Mokrushin 1989).

It is known, that epileptiform seizure reflects the onset of hypersynchronous glutamatergic activation of cortical neurons leading to acute seizures and epilepsy epilepsy (Sun et al. 2001; DeLorenzo et al. 2007). Most seizures are associated with hemorrhagic stroke (Sun et al. 2001; Herman 2002; Silverman et al. 2002; Balami and Buchan 2012) and occur within the first 24 hours of injury (Gilmore et al. 2010; Löscher and Brandt 2010). In cortical and hippocampal (Lehohla et al. 2001; Russell 2001), as well as in olfactory cortex slices (Khama-Murad and Mokrushin 2007), the functional activity of the ionotropic receptors in rats with hypertension (SHRs) is modified due to a functional predominance of NR2B subunit of NMDA receptors (Jensen et al. 2009). We propose that the NMDA synaptic hyperexcitation in piriform neurons of SHR in the early time of the contact with blood is closely associated with such cerebrovascular dysfunction.

Most probably, various blood components penetrating into the brain parenchyma individually or conjointly implicated in the uncontrollable cortical hyperexcitability leading to the seizure generation. Having established the different time course of the glutamate receptor responses in piriform cortex in the experiments with consecutive blood dilution we attempted to discover how the blood components are contributing for depression/excitation and epileptogenesis of neurons, and to establish the time course of their effects in our experimental conditions.

Synaptic responses in slices during perfusion with autologous plasma

Current evidence indicates that ICH-induced brain injury is caused not only by the effects of the hematoma, but also by toxicity from blood components and some of them are more harmful (Xue and Del Bigio 2000; Xi et al. 2006). From clinical observations, it is evident that autologous blood plasma, cellular blood components may spontaneously leak through the damaged walls of blood vessels in the brain tissue in patients at risk (hypertension, age, diabetes, and atherosclerosis) (Vernooij et al. 2008; Vasilevko et al. 2010) . Spreading of injury after ICH are believed to be due to the intraparenchymal accumulation of various blood components following $\mathrm{ICH}$, activating cytotoxic, excitotoxic, oxidative, and inflammatory pathways.

We have established the dual synaptic responses in piriform cortex during perfusion of slices with the autologous blood plasma (Fig. 3). The toxicity of extravasated blood plasma components including blood-derived coagulation factors, complement, thrombin and glutamate argued at minutes after onset of ICH (Wagner et al. 2002; Qureshi et al. 2003; Wagner 2007; Aronowski and Zhao 2011). In our experiments, the majority slices showed a sustained epileptic activity of AMPA and NMDA glutamate receptors in the time of perfusion with plasma (from the onset to $40 \mathrm{~min}$ ). The AMPA and NMDA-mediated excitation with the simultane- 
ous $\mathrm{GABA}_{\mathrm{B}}$ ergic inhibition characterized the overall synaptic response in these slices. The minority of slices manifested the total blockade of the FPs from the onset to the end of the contact with plasma. The reversibility of synaptic responses after washout is indicative of blood plasma action.

Blood plasma infusion induces early edema, oxidative stress, activation of microglia and pro-inflammatory cytokine gene expression $(1 \mathrm{~h}$ ) during ICH (Wang and Tsirka 2005; Wagner et al. 2005). The early activation of microglia in the peri-ICH area (Rosidi et al. 2011; Wagner et al. 2005; Wagner 2007) is linked with extracellular serine-proteases (Wagner et al. 2003; Wang and Doré 2007; Xue and Yong 2008) and observed in brain of SHRs at ICH (Wu et al. 2011). Thrombin - one of such blood-derived proteases involved in mechanisms of brain injury after ICH and modification of its level may coordinate the components of the endogenous response (Xi et al. 2003, 2006; Keep et al. 2011; Badu et al. 2012). The NMDA receptor response is also specified by protease-activated receptor activity (PAR-1) (Gingrich et al. 2000; Hamill et al. 2009). The potentiation of the NMDA receptors by PAR-1 possibly occurs via thrombin activation following ICH (Sharp et al. 2008; Wu et al. 2010). It is yet unclear to which extent the thrombin may contribute to the rapid epileptiform response of NMDA receptors or it may exacerbate glutamate-mediated cell activity in our experiments. Further experiments are required to define these events.

Interstitial plasma (Wang and Doré 2007) and C-reactive proteins (Kuhlmann et al. 2009) implicated in increased blood brain barrier (BBB) permeability in brain. The BBB disruption contributes to the influx of leukocytes and the potentially neuroactive agents into the perihematomal brain during ICH-induced brain injury (Farrall and Wardlaw 2009; Keep et al. 2011) especially in the conditions of neurovascular dysfunction (Kalayci et al. 2009; Amenta et al. 2010). The failure of neuron function correlated with the early ( $1 \mathrm{~h}$ ) destruction of BBB permeability (Shi et al. 2011) during and after epileptic seizures (Marchi et al. 2007), and such uncontrolled BBB disruption may damage the brain parenchyma by enhancing leukocyte influx (Stamatovic et al. 2008). Evidently, the combined effect of plasma on synaptic responses in piriform cortex of SHRs possibly reflects the contradictory influence of the different plasma constituents on neurons with a diverse degree of their activity. It is a sign of ICH-induced brain injury.

\section{Perfusion of slices with fraction of leucocytes}

The effect of BCS on synaptic activity in piriform cortex resembled the influence of autologous blood plasma on a great part of slices. In our conditions, the effect of blood fraction composed of the concentrated leucocytes with some number of platelets was univocal. As we showed in piriform cortex, the persistent NMDA receptor hyperexcitation with the epileptiform discharges occurred at all time of perfusion with the enriched leukocyte fraction (Fig. 4). Evidently, leucocytes may cause a whole-brain injury immediately after ICH (Wagner et al. 2005). They have important effects in early releasing of pro-inflammatory mediators and the platelet-leukocyte-endothelial cell interactions after hemorrhage (MacKenzie and Clayton 1999; Nishikawa et al. 2009; Lok et al. 2011). Apparently, the role of the leucocytes actually consisted in the NMDA receptors firing in combination with their secondary effects.

\section{Effects of the erythrocyte fraction on synaptic responses in} slices

The next step of our study was to clarify the primary effects of the erythrocyte fraction on the synaptic transmission in piriform cortex. The neurotoxicity of red blood cells occurs within hours to days after ICH. Erythrocytes emerged from the hematoma lysis releasing cytotoxic hemoglobin, heme, and iron, thereby initiating secondary processes, which negatively influence the viability of cells surrounding the hematoma (Xi et al. 2001, 2006; Wu et al. 2002; Huang et al. 2002; Wagner et al. 2003; Regan et al. 2008) and the BBB functions (Keep et al. 2008; Katsu et al. 2009). Moreover, at hypertension, intravasal erythrocyte accumulations followed by BBB disturbances often results in microbleeds (Schreiber et al. 2012).

To specify the synaptic activity in brain neurons we used the erythrocytes fraction with the quantity of hemoglobin relevant to whole blood concentration about $5 \mu \mathrm{l}$ of $\mathrm{Hb}$. We found that the activation of the AMPA and NMDA-mediated synaptic responses with fast EDs developed within a few min (1-3) during the erythrocyte fraction perfusion. The excitation of these receptors was replaced by the total depression for the whole period of subsequent perfusion (40 min) (Fig. 5). In spite of such inhibitory effect of the erythrocyte fraction, the nervous cells were still alive because the washout resulted in the FPs components recovery. Similar effect is caused by the reduced-hemoglobin $(100 \mu \mathrm{M})$ and hemin $(50 \mu \mathrm{M})$ in hippocampal slices. The slope of field EPSPs depressed significantly with some recovery following washout (Yip et al. 1996; Yip and Sastry 2000). These results are partly confirmed by the experiments with cortical cell cultures. Early exposure (1-2 h) to hemoglobin was not toxic (Regan and Panter 1993). On the contrary, during perfusion of slices with diluted whole blood ( $3 \mathrm{ml}$ in $50 \mathrm{ml}$ aCSF) we found that the washout failed to evoke the FPs restoration, although the concentration of hemoglobin (about $4 \mu \mathrm{l}$ ) in this case was similar to the same in the tested erythrocyte fraction.

To understand the role of red blood cells in the synaptic responses in piriform cortex we elucidated the role of iron in early events of cellular damage. 
How ferric ions influence on synaptic activity in piriform cortex?

Iron is an important mediator of cellular injury in the brain (Willmore et al. 1978; Wagner et al. 2003, Wu et al. 2003; Zecca et al. 2004; Xi et al. 2006; Wagner 2007; Zhao et al. 2011; Chen et al. 2011). Iron overload leading to oxidative damage of different cell types in brain contributes to the pathogenesis of injury following ICH (Hall et al. 2000; Hua et al. 2006, 2007; Nakamura et al. 2006; Gaasch et al. 2007; Gu et al. 2011).

Minimal free iron level in normal rat brain is about $1 \mu \mathrm{l}$ (Wagner et al. 2003; Wan et al. 2009) and elevation of intracellular iron is acutely toxic to neurons and oligodendrocytes in culture (Kress et al. 2002). Cortical injection of 5-10 $\mu \mathrm{l}$ of ferrous or ferric chloride induced recurrent focal EDs (Willmore et al. 1978) and liberation of glutamate into the neuropil with sequential changes in glutamate transporter mRNA levels as well as in AMPA and NMDA protein levels (Willmore and Ueda 2009; Doi et al. 2000, 2001). In our experimental conditions, the exciting effect of $25 \mu \mathrm{M}$ concentration of $\mathrm{FeCl}_{3}$ started immediately from the onset of perfusion (Fig. $5 \mathrm{~B}$ and $\mathrm{C}$ ) and continued until the washout. We registered the EDs on the NMDA amplitude and the decrease of the AMPA-mediated activity. Peculiarity of the ferric salt effect in piriform cortex consisted in a retention of the $\mathrm{GABA}_{\mathrm{B}^{-}}$ mediated activity of FPs, which maintained also at the high iron concentration $(100 \mu \mathrm{M})$. This iron level resulted in intensifying of the EDs on AMPA and NMDA EPSPs of neurons in piriform cortex. Such acute iron exposure may be a result of brain tissue hypoxia and acidosis that might accompany ICH (Bralet et al. 1992; Lee et al. 1999). On the contrary, in the hippocampal slices ferrous chloride $(50 \mu \mathrm{M}$ and $100 \mu \mathrm{M})$ depressed the field EPSP (Yip and Sastry 2000). This may be due to differences in temperature of the perfusion solution $\left(25^{\circ} \mathrm{C}\right)$ and the effect of $\mathrm{FeCl}_{2}$. An indirect confirmation of the exciting iron effect on synaptic transmission is the significant increase of the amplitude of AMPA-mediated excitatory postsynaptic currents after application of $\mathrm{Fe}^{3+}$ induced a-synuclein oligomers (Hüls et al. 2011).

Thus, we assume that increased neuronal firing in conditions of progressive iron accumulation was a reflection of the retained excitation of the glutamate neuronal receptors, which persisted a long time while heme degradated during the erythrocytes lysis.

The ionotropic receptors are linked to multiple intracellular messengers, such as $\mathrm{Ca}^{2+}$, cyclic AMP, reactive oxygen species, and initiate multiple signaling cascades that determine the neuronal survival during brain damage (Michaelis, 1998; Lai et al. 2011; Lok et al. 2011). Excessive NMDA receptors activation in neurons leads to the production of ROS and to endothelial excitotoxicity associated with a loss of the cerebral endothelial barrier dysfunction and edema forma- tion (Sharp et al. 2003; Betzen et al. 2009). Phosphorylation of NMDA receptors during Src kinase signaling is implicated in multiple mechanisms of ICH including vascular endothelial growth factor and matrix metalloproteinases-mediated changes of vascular permeability (Sharp et al. 2008; Liu et al. 2010). In this context, the possibility of NMDA receptor down regulation with $\mathrm{Src}$ antagonist preventing brain edema and BBB disruption is of interest (Liu and Sharp 2011). We believe that the protection of membrane glutamate receptors may be a promising approach for preventing stroke. The possibility to defend the synaptic activity in brain slices against glutamate excitotoxicity and during the prolonged (to $6 \mathrm{~h}$ ) their contact with autologous blood clot by pretreatment with Hsp70, carnosine and heparin was shown (Mokrushin et al. 2005; Khama-Murad et al. 2011; Mokrushin and Pavlinova 2012a, 2012b).

We can conclude that the early synaptic responses dependent of AMPA and, especially, of NMDA receptor activity induced by the blood components have the different temporal profile in piriform cortex. These temporal modifications of the glutamate synaptic activity may occur in the brain for first minutes after acute ICH and then during hematoma degradation. The primary events happened in these receptors in response to bleeding may explain a mechanism for diffuse brain excitotoxicity and are indicative of necessity of their early or preventive protection. Of course, this assumption can be addressed experimentally, and such studies are currently in progress in our laboratory.

\section{Summary}

The early synaptic responses in brain slices induced by the blood components have the different profile. Plasma, leucocytes and red blood cells reversibly modified the neuron activity in piriform cortex while the effects of whole blood were irreversible. The modifications of the glutamate synaptic activity for first minutes during bleeding possibly connect with the mechanisms of spreading brain excitotoxicity and epileptogenesis.

Acknowledgments. The authors thank Mrs. Galina Smirnova for her excellent technical assistance.

\section{References}

Amenta F., Tayebati S. K., Tomassoni D. (2010): Spontaneously hypertensive rat neuroanatomy: applications to pharmacological research. Ital. J Anat. Embryol. 115, 13-17

Ardizzone T. D., Lu A., Wagner K. R., Tang Y., Ran R., Sharp F. R. (2004): Glutamate receptor blockade attenuates glucose hypermetabolism in perihematomal brain after experimental intracerebral hemorrhage in rat. Stroke 35, 2587-2591 
http://dx.doi.org/10.1161/01.STR.0000143451.14228.ff

Ariesen M. J., Claus S. P., Rinkel G. J., Algra A. (2003): Risk factors for intracerebral hemorrhage in the general population: a systematic review. Stroke 34, 2060-2065 http://dx.doi.org/10.1161/01.STR.0000080678.09344.8D

Aronowski J., Zhao X. (2011): Molecular pathophysiology of cerebral hemorrhage secondary. Brain Injury Stroke 42, $1781-1786$ http://dx.doi.org/10.1161/STROKEAHA.110.596718

Badjatia N., Rosand J. (2005): Intracerebral hemorrhage. Neurologist 11, 311-324 http://dx.doi.org/10.1097/01.nrl.0000178757.68551.26

Badu R., Bagley J. H., Di C., Friedman A. H., Adamson C. (2012): Thrombin and hemin as central factors in the mechanisms of intracerebral hemorrhage-induced secondary brain injury and as potential targets for intervention. Neurosurgical Focus 32, E8 http://dx.doi.org/10.3171/2012.1.FOCUS11366

Balami J. S., Buchan A. M. (2012): Complications of intracerebral haemorrhage. Lancet Neurol. 11, 101-118 http://dx.doi.org/10.1016/S1474-4422(11)70264-2

Betzen C., White R., Zehendner C. M., Pietrowski E., Bender B., Luhmann H. J., Kuhlmann C. R. W. (2009): Oxidative stress upregulates the NMDA receptor on cerebrovascular endothelium. Free Radical Biol. Med. 47, 1212-1220 http://dx.doi.org/10.1016/j.freeradbiomed.2009.07.034

Bralet J., Schreiber L., Bouvier C. (1992): Effect of acidosis and anoxia on iron delocalization from brain homogenates. Biochem. Pharmacol. 43, 979-983 http://dx.doi.org/10.1016/0006-2952(92)90602-F

Chen Y. F., Chang Y. Y., Liu J. S., Lui C. C., Kao Y. F., Lan M. Y. (2008): Association between cerebral microbleeds and prior primary intracerebral hemorrhage in ischemic stroke patients. Clin. Neurol. Neurosurg. 110, 988-991 http://dx.doi.org/10.1016/j.clineuro.2008.06.003

Chen Z., Gao C., Hua Y., Keep R. F., Muraszko K., Xi G. (2011): The role of iron in brain injury after intraventricular hemorrhage. Stroke 42, 465-470 http://dx.doi.org/10.1161/STROKEAHA.110.602755

Cho S., Wood A., Bowlby M. R. (2007): Brain slices as models for neurodegenerative disease and screening platforms to identify novel therapeutics. Curr. Neuropharmacol. 5, 19-33 http://dx.doi.org/10.2174/157015907780077105

Clark J. F., Loftspring M., Wurster W. L., Beiler S., Beiler C., Wagner K. R., Pyne-Geithman G. J. (2008): Bilirubin oxidation products, oxidative stress, and intracerebral hemorrhage. Acta Neurochir. Suppl. 105, 7-12 http://dx.doi.org/10.1007/978-3-211-09469-3_2

DeLorenzo R. J., Sun D. A., Blair R. E., Sombati S. (2007): An in vitro model of stroke-induced epilepsy: elucidation of the roles of glutamate and calcium in the induction and maintenance of stroke-induced epileptogenesis. Int. Rev. Neurobiol. 81, 59-84 http://dx.doi.org/10.1016/S0074-7742(06)81005-6

Doi T., Ueda Y., Tokumaru J., Mitsuyama Y., Willmore L. J. (2000): Sequential changes in glutamate transporter mRNA levels during $\mathrm{Fe}(3+)$-induced epileptogenesis. Brain Res. Mol. Brain Res. 75, 105-112 http://dx.doi.org/10.1016/S0169-328X(99)00303-4
Doi T., Ueda Y., Tokumaru J., Mitsuyama Y., Willmore L. J. (2001): Sequential changes in AMPA and NMDA protein levels during $\mathrm{Fe}(3+)$-induced epileptogenesis. Brain Res. Mol. Brain Res. 92, 107-114 http://dx.doi.org/10.1016/S0169-328X(01)00159-0

Farrall A. J., Wardlaw J. M. (2009): Blood-brain barrier: ageing and microvascular disease- systematic review and meta-analysis. Neurobiol. Aging 30, 337-352 http://dx.doi.org/10.1016/j.neurobiolaging.2007.07.015

Fiehler J. (2006): Cerebral microbleeds: old leaks and new haemorrhages. Int. J. Stroke 1, 122-130 http://dx.doi.org/10.1111/j.1747-4949.2006.00042.x

Gaasch J. A., Lockman P. R., Geldenhuys W. J., Allen D. D., Van der Schyf C. J. (2007): Brain iron toxicity: differential responses of astrocytes, neurons, and endothelial cells. Neurochem. Res. 32, 1196-1208 http://dx.doi.org/10.1007/s11064-007-9290-4

Gilmore E., Choi H. A., Hirsch L. J., Claassen J. (2010): Seizures and CNS hemorrhage: spontaneous intracerebral and aneurysmal subarachnoid hemorrhage. Neurologist 16, 165-175 http://dx.doi.org/10.1097/NRL.0b013e3181c7cd0b

Gingrich M. B., Junge C. E., Lyuboslavsky P., Traynelis S. F. (2000): Potentiation of NMDA receptor function by the serine protease thrombin. J. Neurosci. 20, 4582-4595

Gu Y., Hua Y., He Y., Wang L., Hu H., Keep R. F., Xi G. (2011): Iron accumulation and DNA damage in a pig model of intracerebral hemorrhage. Acta Neurochir. Suppl. 111, 123-128 http://dx.doi.org/10.1007/978-3-7091-0693-8_20

Hall N. C., Packard B. A., Hall C. L., de Courten-Myers G., Wagner K. R. (2000): Protein oxidation and enzyme susceptibility in white and gray matter with in vitro oxidative stress: relevance to brain injury from intracerebral hemorrhage. Cell Mol. Biol. 46, 600-605

Hamill C. E., Mannaioni G., Lyuboslavsky P., Sastre A. A., Traynelis S. F. (2009): Protease- activated receptor 1-dependent neuronal damage involves NMDA receptor function. Exp. Neurol. 217, 136-146 http://dx.doi.org/10.1016/j.expneurol.2009.01.023

Herman S. T. (2002): Epilepsy after brain insult: targeting epileptogenesis. Neurology 59, S21-26 http://dx.doi.org/10.1212/WNL.59.9_suppl_5.S21

Hoffman W. H., Haberly L. B. (1989): Bursing induces persistent all-or-none EPSPs by an NMDA-dependent process in piriform cortex. J. Neurosci. 9, 206-215

Hua Y., Nakamura T., Keep R. F., Wu J., Schallert T., Hoff J. T., Xi G. (2006): Long-term effects of experimental intracerebral hemorrhage: the role of iron. J. Neurosurg. 104, 305-312 http://dx.doi.org/10.3171/jns.2006.104.2.305

Hua Y., Keep R. F., Hoff J. T., Xi G. (2007): Brain injury after intracerebral hemorrhage: the role of thrombin and iron. Stroke 38, 759-762 http://dx.doi.org/10.1161/01.STR.0000247868.97078.10

Huang F., Xi G., Keep R. F., Hua Y., Nemoianu A., Hoff J. T. (2002): Brain edema after experimental intracerebral hemorrhage: role of hemoglobin degradation products. J. Neurosurg. 96, 287-293

http://dx.doi.org/10.3171/jns.2002.96.2.0287

Hüls S., Högen T., Vassallo N., Danzer K. M., Hengerer B., Giese A., Herms J. (2011): AMPA- receptor-mediated excitatory synaptic 
transmission is enhanced by iron-induced $\alpha$ - synuclein oligomers. J. Neurochem. 117, 868-878 http://dx.doi.org/10.1111/j.1471-4159.2011.07254.x

Jensen V., Rinholm J.E., Johansen T. J., Medin T., Storm-Mathisen J., Sagvolden, T., Hvalby, O., Bergersen, L. H. (2009): N-methyl-D-aspartate receptor subunit dysfunction at hippocampal glutamatergic synapses in an animal model of attention-deficit/ hyperactivity disorder. Neuroscience 158, 353-364 http://dx.doi.org/10.1016/j.neuroscience.2008.05.016

Jung M. W., Larson J., Lynch G. (1990): Role of NMDA and nonNMDA receptors in synaptic transmission in rat piriform cortex. Exp. Brain Res. 82, 451-455 http://dx.doi.org/10.1007/BF00231264

Kalayci R., Kaya M., Uzun H., Bilgic B., Ahishali B., Arican N., Elmas I., Küçük M. (2009): Influence of hypercholesterolemia and hypertension on the integrity of the blood-brain barrier in rats. Int. J. Neurosci. 119, 1881-1904 http://dx.doi.org/10.1080/14647270802336650

Katsu M., Niizuma K., Yoshioka H., Okami N., Sakata H., Chan P. H. (2010): Hemoglobin- induced oxidative stress contributes to matrix metalloproteinase activation and blood- brain barrier dysfunction in vivo. J. Cereb. Blood Flow Metab. 30, 1939-1950 http://dx.doi.org/10.1038/jcbfm.2010.45

Keep R. F., Xiang J., Ennis S. R., Andjelkovic A., Hua Y., Xi G., Hoff J. T. (2008): Blood- brain barrier function in intracerebral hemorrhage. Acta Neurochirurgica Suppl. 105, 73-77 http://dx.doi.org/10.1007/978-3-211-09469-3_15

Keep R. F., Xi G., Hua Y., Xiang J. (2011): Clot formation, vascular repair and hematoma resolution after $\mathrm{ICH}$, a coordinating role for thrombin? Acta Neurochir. Suppl. 111, 71-75 http://dx.doi.org/10.1007/978-3-7091-0693-8_12

Khama-Murad A. Kh., Mokrushin A. A. (2007): Stable hypertension modifies glutamatergic and GABA-ergic synaptic transmission in the rat olfactory brain cortex in vitro. Dokl. Biol. Sci. 418, 1-4

Khama-Murad A. Kh., Mokrushin A. A., Pavlinova L. I. (2011): Neuroprotective properties of L- carnosine in the brain slices exposed to autoblood in the hemorrhagic stroke model in vitro. Regulatory Peptides 167, 65-69

http://dx.doi.org/10.1016/j.regpep.2010.11.007

Kress G. J., Dineley K. E., Reynolds I. J. (2002): The relationship between intracellular free iron and cell injury in cultured neurons, astrocytes, and oligodendrocytes. J. Neurosci. 22, 5848-5855

Kuhlmann C. R. W., Librizzi L., Closhen D., Pflanzner T., Lessmann V., Pietrzik C. U., de Curtis M. D., Luhmann H. J. (2009): Mechanisms of C-reactive protein-induced blood-brain barrier disruption. Stroke 40, 1458-1466 http://dx.doi.org/10.1161/STROKEAHA.108.535930

Lai T. W., Shyu W. C., Wang Y. T. (2011): NMDA receptors and beyond. Trends Mol. Med. 17, 266-275 http://dx.doi.org/10.1016/j.molmed.2010.12.008

Lau A., Tymianski M. (2010): Glutamate receptors, neurotoxicity and neurodegeneration. Eur. J. Physiol. 460, 525-542 http://dx.doi.org/10.1007/s00424-010-0809-1

Lee E. J., Hung Y. C., Lee M. Y. (1999): Anemic hypoxia in moderate intracerebral hemorrhage: the alterations of cerebral hemodynamics and brain metabolism. J. Neurol. Sci. 164, 117-123
http://dx.doi.org/10.1016/S0022-510X(99)00068-4

Lee S. H., Bae H. J., Kwon S. J., Kim H., Kim Y. H., Yoon B. W., Roh J. K. (2004): Cerebral microbleeds are regionally associated with intracerebral hemorrhage. Neurology 62, 72-76 http://dx.doi.org/10.1212/01.WNL.0000101463.50798.0D

Lehohla M., Russell V., Kellaway L. (2001): NMDA-stimulated Ca2+ uptake into barrel cortex slices of spontaneously hypertensive rats. Metab. Brain Disease 16, 133-141 http://dx.doi.org/10.1023/A:1012532709306

Liu Y., Wong T. P., Aarts M., Rooyakkers A., Liu L., Lai T. W., Wu D. C., Lu J., Tymianski M., Craig A. M., Wang Y. T. (2007): NMDA receptor subunits have differential roles in mediating excitotoxic neuronal death both in vitro and in vivo. J. Neurosci. 27, 2846-2857 http://dx.doi.org/10.1523/JNEUROSCI.0116-07.2007

Liu D. Z., Ander B. P., Xu H., Shen Y., Kaur P., Deng W., Sharp F. R. (2010): Blood-brain barrier breakdown and repair by Src after thrombin-induced injury. Ann Neurol. 67, 526-533 http://dx.doi.org/10.1002/ana.21924

Liu D. Z., Sharp F. R. (2011): The dual role of SRC kinases in intracerebral hemorrhage. Acta Neurochir. Suppl. 111, 77-81 http://dx.doi.org/10.1007/978-3-7091-0693-8_13

Lok J., Leung W., Murphy S., Butler W., Noviski N., Lo E. H. (2011): Intracranial hemorrhage: mechanisms of secondary brain injury. Acta Neurochir. Suppl. 111, 63-69

http://dx.doi.org/10.1007/978-3-7091-0693-8_11

Löscher W., Brandt C. (2010): Prevention or modification of epileptogenesis after brain insults: experimental approaches and translational research. Pharmacol. Rev. 62, 668-700 http://dx.doi.org/10.1124/pr.110.003046

MacKenzie J. M., Clayton J. A. (1999): Early cellular events in the penumbra of human spontaneous intracerebral hemorrhage. J. Stroke Cerebrovasc. Dis. 8, 1-8 http://dx.doi.org/10.1016/S1052-3057(99)80032-9

Marchi N., Angelov L., Masaryk T., Fazio V., Granata T., Hernandez N., Hallene K., Diglaw T., Franic L., Najm I., Janigro D. (2007): Seizure-promoting effect of blood-brain barrier disruption. Epilepsia 48, 732-742 http://dx.doi.org/10.1111/j.1528-1167.2007.00988.x

Michaelis E. K. (1998): Molecular biology of glutamate receptors in the central nervous system and their role in excitotoxicity, oxidative stress and aging. Prog. Neurobiol. 54, 369-415 http://dx.doi.org/10.1016/S0301-0082(97)00055-5

Mokrushin A. A. (1997): Peptide-dependent mechanisms of neural plasticity in olfactory cortex slices. Diss. Doctor. Sci., SaintPetersburg, Pavlov Institute Physiology Russian Academy of Sciences. 341

Mokrushin A. A, Pavlinova L. I, Plekhanov A. Y. (2005): Heat shock protein HSP70 increases the resistance of cortical cells to glutamate excitotoxicity. Bull. Exp. Biol. Med. 140, 1-5 http://dx.doi.org/10.1007/s10517-005-0396-x

Mokrushin A. A., Pavlinova L. I. (2012a): Effects of heparin on synaptic activity in the hemorrhagic stroke model in vitro. Bull. Exper. Biol. Med. 152, 684-687 http://dx.doi.org/10.1007/s10517-012-1606-y

Mokrushin A. A., Pavlinova L. I. (2012b): Hsp70 promotes synaptic transmission in the brain slices damaged by the contact with blood clot. Eur. J. Pharmacol. 677, 55-62 
http://dx.doi.org/10.1016/j.ejphar.2011.12.004

Musiashchikova S. S., Mokrushin A. A. (1989): Electrophysiological analysis of the spectrum of the fibers of the lateral olfactory tract in rats in vitro. Izv. Akad. Nauk SSSR Biol. 3, 458-461 (in Russian)

Nakamura T., Keep R. F., Hua Y., Nagao S., Hoff J. T., Xi G. (2006): Iron-induced oxidative brain injury after experimental intracerebral hemorrhage. Acta Neurochir. Suppl. 96, 194-198 http://dx.doi.org/10.1007/3-211-30714-1_42

Nishikawa T., Ueba T., Kajiwara M., Miyamatsu N., Yamashita K. (2009): Cerebral microbleeds in patients with intracerebral hemorrhage are associated with previous cerebrovascular diseases and white matter hyperintensity, but not with regular use of antiplatelet agents. Neurol. Med. Chir. 49, 333-338 http://dx.doi.org/10.2176/nmc.49.333

Poels M. M., Vernooij M. W., Ikram M. A., Hofman A., Krestin G. P, van der Lugt A., Breteler M. M. (2010): Prevalence and risk factors of cerebral microbleeds: an update of The Rotterdam scan study. Stroke 41, S103-106

http://dx.doi.org/10.1161/STROKEAHA.110.595181

Qureshi A. I., Ali Z., Suri M. F., Shuaib A., Baker G., Todd K., Guterman L. R., Hopkins L. N. (2003): Extracellular glutamate and other amino acids in experimental intracerebral hemorrhage: an in vivo microdialysis study. Crit. Care Med. 31, 1482-1489

http://dx.doi.org/10.1097/01.CCM.0000063047.63862.99

Qureshi A. I., Mendelow A. D., Hanley D. F. (2009): Intracerebral hemorrhage. Lancet 373, 1632-1644

http://dx.doi.org/10.1016/S0140-6736(09)60371-8

Regan R. F., Panter S. S. (1993): Neurotoxicity of hemoglobin in cortical cell culture. Neurosci. Lett. 153, 219-222 http://dx.doi.org/10.1016/0304-3940(93)90326-G

Regan R. F., Chen M., Li Z., Zhang X., Benvenisti-Zarom L., ChenRoetling J. (2008): Neurons lacking iron regulatory protein-2 are highly resistant to the toxicity of hemoglobin. Neurobiol. Dis. 31, 242-249 http://dx.doi.org/10.1016/j.nbd.2008.04.008

Rosidi N. L., Zhou J., Pattanaik S., Wang P., Jin W., Brophy M., Olbricht W. L., Nishimura N., Schaffer C. B. (2011): Cortical microhemorrhages cause local inflammation but do not trigger widespread dendrite degeneration. PLoS One 6, 26612 http://dx.doi.org/10.1371/journal.pone.0026612

Russell V. A. (2001): Increased AMPA receptor function in slices containing the prefrontal cortex of spontaneously hypertensive rats. Metab. Brain Dis. 16, 143-149 http://dx.doi.org/10.1023/A:1012584826144

Satou M., Mori K., Tazawa Y., Takagi S. F. (1982): Two types of postsynaptic inhibition in pyriform cortex of the rabbit: fast and slow inhibitory postsynaptic potentials. J. Neurophysiol. 48, 1142-1156

Schreiber S., Bueche C. Z., Garz C., Kropf S., Angenstein F., Goldschmidt J., Neumann J., Heinze H. J., Goertler M., Reymann K. G., Braun H. (2012): The pathologic cascade of cerebrovascular lesions in SHRSP:is erythrocyte accumulation an early phase? J. Cereb Blood Flow Metab. 32, 278-290 http://dx.doi.org/10.1038/jcbfm.2011.122

Sharp C. D., Hines I., Houghton J., Warren A., Jackson T. H. IV, Jawahar A., Nanda A., Elrod J. W., Long A., Chi A., Minagar
A., Alexander J. S. (2003):Glutamate causes a loss in human cerebral endothelial barrier integrity through activation of NMDAR. Am. J. Physiol. Heart Circ. Physiol. 285, H2592-2598

Sharp F., Liu D. Z., Zhan X., Ander B. P. (2008): Intracerebral hemorrhage injury mechanisms: glutamate neurotoxicity, thrombin, and Src. Acta Neurochir. Suppl. 105, 43-46

http://dx.doi.org/10.1007/978-3-211-09469-3_9

Shi W., Wang Z., Pu J., Wang R., Guo Z., Liu C., Sun J., Gao L., Zhou R. (2011): Changes of blood-brain barrier permeability following intracerebral hemorrhage and the therapeutic effect of minocycline in rats. Acta Neurochir. Suppl. 110, 61-67

Silverman I. E., Restrepo L., Mathews G. C. (2002): Poststroke seizures. Arch. Neurol. 59, 195-201 http://dx.doi.org/10.1001/archneur.59.2.195

Stamatovic S. M., Keep R. F., Andjelkovic A. V. (2008): Brain endothelial cell-cell junctions: how to „open“ the blood brain barrier. Curr. Neuropharmacol. 6, 179-192 http://dx.doi.org/10.2174/157015908785777210

Sun D. A., Sombati S., DeLorenzo R. J. (2001): Glutamate injuryinduced epileptogenesis in hippocampal neurons: an in vitro model of stroke-induced „epilepsy“. Stroke 32, 2344-2350 http://dx.doi.org/10.1161/hs1001.097242

Tseng G. F., Haberly L. B. (1988): Characterization of synaptically mediated fast and slow inhibitory processes in piriform cortex in an in vitro slice preparation. J. Neurophysiol. 59, $1352-1376$

Ueno M. (2009): Mechanisms of the penetration of blood-borne substances into the brain. Curr. Neuropharmacol. 7, 142-149 http://dx.doi.org/10.2174/157015909788848901

Vasilevko V., Passos G. F., Quiring D., Head E., Kim R. C., Fisher M., Cribbs D. H. (2010): Aging and cerebrovascular dysfunction: contribution of hypertension, cerebral amyloid angiopathy, and immunotherapy. Ann. N. Y. Acad. Sci. 1207, 58-70 http://dx.doi.org/10.1111/j.1749-6632.2010.05786.x

Vernooij M. W., van der Lugt A., Ikram M. A., Wielopolski P. A., Niessen W. J., Hofman A., Krestin G. P., Breteler M. M. (2008): Prevalence and risk factors of cerebral microbleeds: the Rotterdam Scan Study. Neurology 70, 1208-1214 http://dx.doi.org/10.1212/01.wnl.0000307750.41970.d9

Wagner K. R., Packard B. A., Hall C. L., Smulian A. G., Linke M. J., De Courten-Myers G. M., Packard L. M., Hall N. C. (2002): Protein oxidation and heme oxygenase- 1 induction in porcine white matter following intracerebral infusions of whole blood or plasma. Dev. Neurosci. 24, 154-160 http://dx.doi.org/10.1159/000065703

Wagner K. R., Sharp F. R., Ardizzone T. D., Lu A., Clark J. F. (2003): Heme and iron metabolism: role in cerebral hemorrhage. J. Cereb. Blood Flow Metab. 23, 629-652 http://dx.doi.org/10.1097/01.WCB.0000073905.87928.6D

Wagner K. R., Dean C., Beiler S., Bryan D. W., Packard B. A., Smulian A. G., Linke M. J., de Courten-Myers G. M. (2005): Plasma infusions into porcine cerebral white matter induce early edema, oxidative stress, pro-inflammatory cytokine gene expression and DNA fragmentation: implications for white matter injury with increased blood-brain- barrier permeability. Curr. Neurovasc. Res. 2, 149-155 http://dx.doi.org/10.2174/1567202053586785 
Wagner K. R. (2007): Modeling intracerebal hemorrhage glutamate, nuclear factor-kB signaling and cytokines. Stroke 38, 753-758 http://dx.doi.org/10.1161/01.STR.0000255033.02904.db

Wan S., Zhan R., Zheng S., Hua Y., Xi G. (2009): Activation of c-Jun$\mathrm{N}$-terminal kinase in a rat model of intracerebral hemorrhage: the role of iron. Neurosci. Res. 63, 100-105 http://dx.doi.org/10.1016/j.neures.2008.10.013

Wang J., Tsirka S. E. (2005): Contribution of extracellular proteolysis and microglia to intracerebral hemorrhage. Neurocrit. Care 3, 77-85 http://dx.doi.org/10.1385/NCC:3:1:077

Wang J., Doré S. (2007): Inflammation after intracerebral hemorrhage. J. Cereb. Blood Flow Metab. 27, 894-908

Willmore L. J., Sypert G. W., Munson J. B., Hurd R. W. (1978): Chronic focal epileptiform discharges induced by injection of iron into rat and cat cortex. Science 200, 1501-1503 http://dx.doi.org/10.1126/science.96527

Wu J., Hua Y., Keep R. F., Schallert T., Hoff J. T., Xi G. (2002): Oxidative brain injury from extravasated erythrocytes after intracerebral hemorrhage. Brain Res. 953, 45-52 http://dx.doi.org/10.1016/S0006-8993(02)03268-7

Wu J., Hua Y., Keep R. F., Nakamura T., Hoff J. T., Xi G. (2003): Iron and iron-handling proteins in the brain after intracerebral hemorrhage. Stroke 34, 2964-2969 http://dx.doi.org/10.1161/01.STR.0000103140.52838.45

Wu H., Zhang Z., Li Y., Zhao R., Li H., Song Y., Qi J., Wang J. (2010): Time course of upregulation of inflammatory mediators in the hemorrhagic brain in rats: correlation with brain edema. Neurochem. Int. 57, 248-253 http://dx.doi.org/10.1016/j.neuint.2010.06.002

Wu G., Bao X., Xi G., Keep R. F., Thompson B. G., Hua Y. (2011): Brain injury after intracerebral hemorrhage in spontaneously hypertensive rats. J. Neurosurg. 114, 1805-1811 http://dx.doi.org/10.3171/2011.1.JNS101530

Xi G., Hua Y., Bhasin R. R., Ennis S. R., Keep R. F., Hoff J. T. (2001): Mechanisms of edema formation after intracerebral hemorrhage: effects of extravasated red blood cells on blood flow and blood-brain barrier integrity. Stroke 32, 2932-2938 http://dx.doi.org/10.1161/hs1201.099820
Xi G., Reiser G., Keep R. F. (2003): The role of thrombin and thrombin receptors in ischemic, hemorrhagic and traumatic brain injury:deleterious or protective? J. Neurochem. 84, 3-9 http://dx.doi.org/10.1046/j.1471-4159.2003.01268.x

Xi G., Keep R. F., Hoff J. T. (2006): Mechanisms of brain injury after intracerebral haemorrhage. Lancet Neurol. 5, 53-63 http://dx.doi.org/10.1016/S1474-4422(05)70283-0

Xue M., Del Bigio M. R. (2000): Intracortical hemorrhage injury in rats. Relationship between blood fractions and brain cell death. Stroke 31, 1721-1727 http://dx.doi.org/10.1161/01.STR.31.7.1721

Xue M., Yong V. W. (2008): Matrix metalloproteinases in intracerebral hemorrhage. Neurol. Res. 30, 775-782 http://dx.doi.org/10.1179/174313208X341102

Yip S., Ip J. K., Sastry B. R.(1996): Electrophysiological actions of hemoglobin on rat hippocampal CA1 pyramidal neurons. Brain Res. 713, 134-142 http://dx.doi.org/10.1016/0006-8993(95)01499-3

Yip S., Sastry B. R. (2000): Effects of hemoglobin and its breakdown products on synaptic transmission in rat hippocampal CA1 neurons. Brain Res. 864, 1-12 http://dx.doi.org/10.1016/S0006-8993(00)02067-9

Zecca L., Youdim M. B., Riederer P., Connor J. R., Crichton R. R. (2004): Iron, brain ageing and neurodegenerative disorders. Nat. Rev. Neurosci. 5, 863-573 http://dx.doi.org/10.1038/nrn1537

Zhao F., Song S., Liu W., Keep R. F., Xi G., Hua Y. (2011): Red blood cell lysis and brain tissue- type transglutaminase upregulation in a hippocampal model of intracerebral hemorrhage. Acta Neurochir. Suppl. 111, 101-105 http://dx.doi.org/10.1007/978-3-7091-0693-8_16

Zia E., Pessah-Rasmussen H., Khan F. A., Norrving B., Janzon L., Berglund G., Engstrom G. (2006): Risk factors for primary intracerebral hemorrhage: a population-based nested casecontrol study. Cerebrovasc. Dis. 21, 18-25

http://dx.doi.org/10.1159/000089589

Received: December 4, 2012

Final version accepted: February 18, 2013 